\title{
Pengaruh Profil Demografis Terhadap Keberhasilan Pelatihan Pengolahan Pupuk Organik di Kecamatan Ngadirojo Kabupaten Wonogiri
}

\author{
S. Emawati ${ }^{1,2^{*}}$, Sudiyono ${ }^{1,2}$, A. I. Sari ${ }^{1,2}$ \\ ${ }^{1}$ Program Studi Peternakan, Fakultas Pertanian, Universitas Sebelas Maret (UNS) \\ ${ }^{2}$ Pusat Penelitian dan Pengembangan Pangan Gizi dan Kesehatan Masyarakat (P4GKM) LPPM UNS
}

\begin{abstract}
ABSTRAK
Tujuan dari penelitian ini adalah untuk menganalisis pengaruh profil demografis terhadap keberhasilan pelatihan pengolahan pupuk organik di Kecamatan Ngadirojo Kabupaten Wonogiri. Penelitian dilaksanakan di Kecamatan Ngadirojo, Kabupaten Wonogiri pada tanggal 1 Agustus - 28 September 2016. Desain penelitian yang digunakan adalah metode PreExperimental Design dengan One Group Pretest dan Posttest Design. Teknik penentuan lokasi penelitian dan responden adalah purposive sampling. Data yang digunakan meliputi data primer dari responden yaitu peternak sapi potong yang mengikuti pelatihan pengolahan pupuk organik dan data sekunder yang diperoleh dari dinas terkait. Analisis data yang digunakan adalah analisis uji paired $t$ test dan analisis regresi linier berganda. Berdasarkan hasil penelitian menunjukkan bahwa variabel tingkat pendidikan, usia peternak, jumlah kepemilikan ternak dan pekerjaan peternak secara bersama-sama berpengaruh terhadap keberhasilan pelatihan pengolahan pupuk organik, sedangkan variabel tingkat pendidikan, usia peternak, jumlah kepemilikan ternak dan pekerjaan peternak secara parsial tidak berpengaruh terhadap keberhasilan pelatihan pengolahan pupuk organik.
\end{abstract}

Kata Kunci: peternak, pelatihan, pupuk organik, pengetahuan

\section{Impact of Demographic Profile to Acceptability of the Training of Organic Fertilizer Processing in Ngadirojo, Wonogiri}

\section{ABSTRACT}

The aim of this study was to analyse the impact of demographic profile to acceptability of the training of organic fertilizer processing in Ngadirejo, Wonogiri. This study was performed in Ngadirejo, Wonogiri, at Agustus 1 to September 28, 2016. The design of this study was pre-experimental design with one group pretest and posttest design. Techniques for location and respondent determinations were purposive sampling. The data used in this study consisted primary data collected from beef cattle farmers who follow the tarining of organic fertilizer processing and secondary data which is obtained from related agencies. The data has been analyzed using paired sample t test and multiple linear regressions. The results showed that education level, age, the number of animal had by farmer, and occupation of the farmers collectively affected acceptability of the organic fertilizer processing training, on the other hand, education level, age, the number of animal had by farmer, and occupation of the farmers partially did not affect acceptability of the organic fertilizer processing training.

Keywords: Farmer, Knowledge, Organic fertilizer, Training

\section{PENDAHULUAN}

Dewasa ini pola kebijakan pengembangan usaha sapi potong di Indonesia masih berorientasi pada pola peternakan rakyat atau keluarga. Usaha sapi potong rakyat sebagian besar merupakan usaha yang bersifat turun-temurun dengan pola pemeliharaan sesuai dengan kemampuan peternak (Aryogi et al., 2000). Yusdja et al. (2001) menyatakan bahwa usaha peternakan sapi potong rakyat ini memiliki posisi yang lemah dan sangat peka terhadap perubahan, sehingga suatu pemberdayaan masyarakat sangat diperlukan bagi keberadaan peternakan sapi potong rakyat untuk pengembangan usahanya. Salah satu upaya pemberdayaan masyarakat adalah melalui kegiatan penyuluhan dan pelatihan yang diikuti peternak dalam rangka meningkatkan kemampuan dan kemandirian peternak (Tiafery, 2016).

\footnotetext{
*Penulis Korespondensi: S. Emawati

Alamat: Jl. Ir. Sutami 36A Kentingan, Surakarta, Jawa Tengah

E-mail: shanti_uns@yahoo.co.id
}

Kecamatan Ngadirojo merupakan salah satu kecamatan yang berada di Kabupaten Wonogiri, Provinsi Jawa Tengah. Kecamatan Ngadirojo memiliki luas wilayah sebesar 9.325 .556 ha yang terbagi menjadi 11 desa/kelurahan. Jumlah penduduk di Kecamatan Ngadirojo pada tahun 2011 sebanyak 65.722 jiwa, terdiri dari 32838 jiwa penduduk laki-laki dan 32.884 jiwa penduduk perempuan. Secara administratif Kecamatan Ngadirojo mempunyai batasbatas wilayah yaitu sebelah utara berbatasan dengan Kabupaten Kabupaten Karanganyar, sebelah selatan berbatasan dengan Kecamatan Nguntoronadi, sebelah barat berbatasan dengan Kecamatan Wonogiri dan sebelah timur dengan Kecamatan Sidoharjo (BPS Ngadirojo, 2012).

Kecamatan Ngadirojo merupakan salah satu wilayah yang mempunyai potensi dalam usaha penggemukan sapi potong. Kondisi lahannya dimanfaatkan masyarakatnya sebagai lahan pertanian sehingga hasil dari pertanian maupun tegalannya dapat dimanfaatkan sebagai pakan ternak. Limbah kotoran 
yang berasal dari ternak sapi digunakan sebagai pupuk untuk penyubur tanaman pangan dan pakan.

Karakteristik peternak dapat menggambarkan keadaan peternak yang berhubungan dengan keterlibatannya dalam mengelola usaha ternak. Karakteristik peternak bisa mempengaruhi dalam hal mengadopsi suatu inovasi, salah satu nya inovasi dalam pengolahan pupuk organic. Karakteristik peternak sebagai individu yang perlu diperhatikan untuk melihat apakah faktor-faktor ini akan memengaruhi respon peternak terhadap inovasi yang diperkenalkan. Simamora (2006) mengatakan bahwa karakteristik seseorang memengaruhi cara dan kemampuan yang berbeda dalam bentuk persepsi, informasi apa yang diinginkan, bagaimana menginterpretasi informasi tersebut.

Menurut Soekartawi (1995), cepat tidaknya petani mengadopsi inovasi sangat bergantung kepada faktor sosial dan ekonomi petani. Faktor sosial diantaranya: umur, tingkat pendidikan, dan pengalaman bertani, sedangkan faktor ekonomi diantaranya: tingkat pendapatan, jumlah tanggungan keluarga, luas lahan yang dimiliki dan ada tidaknya usahatani yang dimiliki petani. Baba et al. (2011) menyatakan bahwa karakteristik peternak yang terdiri dari umur, tingkat pendidikan formal, tingkat kosmopolit dan pengalaman usaha memengaruhi partisipasi peternak dalam kegiatan penyuluhan.

Berdasarkan latar belakang tersebut maka perlu dilakukan penelitian mengenai pengaruh karakteristik peternak yang meliputi tingkat pendidikan, usia, jumlah kepemilikan ternak dan pekerjaan peternak terhadap pelatihan pengolahan pupuk organik di Kecamatan Ngadirojo Kabupaten Wonogiri, Provinsi Jawa Tengah.

\section{MATERI DAN METODE}

\section{Waktu dan Lokasi Penelitian}

Penelitian dilaksanakan pada tanggal 1 Agustus 28 September 2016 di Kecamatan Ngadirojo, Kabupaten Wonogiri, Provinsi Jawa Tengah.

\section{Desain Penelitian}

Desain penelitian ini menggunakan PreExperimental Design dengan One Group Pretest dan Posttest Design yang menggunakan seluruh kelompok subjek untuk diberi perlakuan tanpa ada kelompok pembanding. Desain ini dilakukan dengan membandingkan hasil pretest dan posttest dari responden sebagai peserta pelatihan pengolahan pupuk organik.

\section{Teknik Penentuan Sampel}

Penentuan lokasi penelitian dan responden dilakukan secara sengaja (purposive) berdasarkan pertimbangan-pertimbangan tertentu yang diambil berdasarkan pada ciri-ciri atau sifat-sifat yang diketahui sebelumnya sesuai dengan tujuan penelitian (Singarimbuan dan Effendi, 1997). Lokasi penelitian dipilih Kecamatan Ngadirojo, Kabupaten Wonogiri karena merupakan salah satu wilayah yang memiliki potensi usaha peternakan sapi potong.

Penentuan sampel ditentukan dengan metode purposive (sengaja) yaitu peternak di Kecamatan Ngadirojo yang mengikuti pelatihan pengolahan pupuk organik dan mampu menerapkan pengetahuan yang diperoleh selama pelatihan. Peneliti menganggap sampel yang dipilih tersebut dapat memberikan informasi dalam mendukung penelitian ini (Sunyoto, 2009).

\section{Jenis dan Sumber Data}

Data primer adalah data yang dikumpulkan langsung oleh peneliti dari para responden, sedangkan data sekunder adalah data-data pendukung yang diperoleh dari buku-buku, maupun sumber lain yang diterbitkan oleh instansi terkait.

\section{Teknik Pengumpulan Data}

Teknik pengumpulan data meliputi wawancara, observasi, studi pustaka, pencatatan dan pretest dan posttest.

\section{Analisis Data}

Paired $\boldsymbol{t}$ test. Teknik analisis statistik yang digunakan untuk mengetahui peningkatan pengetahuan peternak dalam pelatihan pengolahan pupuk organik adalah Paired t Test (uji beda rata-rata untuk sampel yang berhubungan). Metode ini menggambarkan bahwa responden akan diukur tes pengetahuannya sebelum pelatihan (nilai pretest) dan diukur tes pengetahuannya setelah pelatihan (nilai post test) selanjutnya nilai masing-masing responden dibandingkan antara sebelum pelatihan (pre test) dengan setelah pelatihan (post test) (Handoko, 2009). Rumus Paired t test:

Keterangan:

$$
t=\frac{\mathrm{D}}{\mathrm{Sd} / \sqrt{\mathrm{n}}}
$$

$\mathrm{t}=$ Koefisien Paired $\mathrm{t}$ Test

$\mathrm{D}$ = rata-rata dari beda antara nilai pre dan post

$\mathrm{Sd}=$ simpangan baku dari $\mathrm{D}$

Analisis regresi linier berganda. Penelitian ini bersifat penjelasan (eksplanatory) yang menganalisis faktor-faktor apa saja yang dapat mempengaruhi keberhasilan pelatihan (Budiono, 2002). Menurut Kutner (2004) analisis regresi linier berganda dirumuskan sebagai berikut:

$$
\mathrm{Y}=\mathrm{a}+\beta 1 \mathrm{X} 1+\beta 2 \mathrm{X} 2+\beta 3 \mathrm{X} 3+\beta 4 \mathrm{X} 4+\mathrm{e}
$$

Keterangan:

$\mathrm{Y}=$ Keberhasilan pelatihan

$\mathrm{a}=$ Konstanta

$\beta 1, \beta 2, \beta 3, \beta 4=$ Koefisien Regresi

$\mathrm{X} 1=$ variabel pendidikan peternak

$\mathrm{X} 2$ = variabel usia peternak

$\mathrm{X} 3$ = variabel jumlah kepemilikan ternak

$\mathrm{X} 4$ = variabel pekerjaan peternak

$\mathrm{e}=$ Error 
Tabel 1. Karakteristik peserta pelatihan di Kecamatan Ngadirojo Kabupaten Wonogiri

\begin{tabular}{ccc}
\hline \hline Umur (tahun) & Jumlah (Orang) & Persentase (\%) \\
\hline$\leq 20$ & 0 & 0 \\
$21-40$ & 11 & 34,38 \\
$41-60$ & 16 & 5 \\
$>60$ & 5 & 15,63 \\
\hline Total & 32 & 100 \\
\hline Tingkat pendidikan & Jumlah (orang) & Persentase (\%) \\
\hline SD & 15 & 36,88 \\
SMP & 11 & 15,38 \\
SMA & 5 & 3,13 \\
\hline Perguruan Tinggi & 1 & 100 \\
\hline Total & 32 & Persentase $(\%)$ \\
\hline Skala usaha (ekor) & Jumlah (orang) & 21,88 \\
\hline $0-1$ & 7 & 71,88 \\
$2-4$ & 23 & 12,5 \\
\hline$>4$ & 4 & 100 \\
\hline Total & 32 & Persentase $(\%)$ \\
\hline Pekerjaan peternak & Jumlah (orang) & 68,75 \\
\hline Petani & 22 & 12,5 \\
Buruh & 4 & 12,5 \\
Wiraswasta & 4 & 3,13 \\
Guru & 1 & 3,13 \\
\hline Kaur & 1 & 100 \\
\hline & 32 &
\end{tabular}

\section{Sumber: Data primer terolah, 2016}

\section{Uji Statistik}

Uji kelayakan suatu model digunakan untuk mengukur ketepatan fungsi regresi sampel dalam menaksir nilai aktual secara statistik, setidaknya hal ini dapat diukur dari nilai koefisien determinasi, nilai statistik F dan nilai statistik t (Ghozali, 2011).

Uji signifikansi simultan (uji statistik F). Uji statistik $F$ pada dasarnya digunakan untuk mengetahui apakah model regresi dapat digunakan untuk memprediksi variabel dependen atau tidak (Priyatno, 2008).

- $\quad$ Ho = Variabel independen secara bersama-sama tidak berpengaruh secara signifikan terhadap variabel dependen.

- $\quad \mathrm{Ha}=$ Variabel independen secara bersama-sama berpengaruh signifikan terhadap variabel dependen.

Uji signifikansi parameter individual (uji statistik t). Uji statistik t pada dasarnya menunjukkan seberapa jauh pengaruh satu variabel independen secara individual dalam menerangkan variasi variabel dependen (Ghozali, 2011).

Uji koefisien determinasi $\left(\mathbf{R}^{2}\right)$. Koefisien determinasi menyatakan ukuran ketepatan atau kecocokan suatu garis regresi yang diterapkan terhadap suatu kelompok data hasil penelitian dan digunakan untuk mengetahui proporsi keragaman total peubah respon yang diterangkan oleh beberapa peubah penjelas secara bersama-sama (Ghozali, 2011). Koefisien determinasi $\left(\mathrm{R}^{2}\right)$ pada intinya mengukur seberapa jauh kemampuan sebuah model menerangkan variasi variabel dependen.

Nilai koefisien determinasi adalah antara nol dan satu. Nilai $\mathrm{R}^{2}$ yang kecil berarti kemampuan variabelvariabel independen dalam menjelaskan variabel dependen sangat terbatas. Nilai yang mendekati satu berarti variabel-variabel independen memberikan hampir semua. Koefisien determinasi (R2) pada intinya mengukur seberapa jauh kemampuan model dalam menerangkan variasi peubah terikat.

\section{HASIL DAN PEMBAHASAN}

\section{Karakteristik Peternak}

Usia peternak dalam penelitian ini rata-rata adalah 48 tahun dengan kisaran usia 41-60 tahun sebanyak 16 orang. Usia peternak yang mengikuti pelatihan dapat dilihat pada Tabel 1. Usia responden tersebut tergolong tergolong usia produktif untuk bekerja. Hasil tersebut didukung Undang-Undang Tenaga Kerja Nomor 13 Tahun 2003, seseorang yang dikelompokkan sebagai tenaga kerja berusia 15

Tabel 2. Hasil paired t test

\begin{tabular}{lccccc}
\hline \hline & Mean & N & Std deviation & T hitung & P \\
\hline Posttest & 61,69 & 32 & 23,37 & 47,04 & 0,001 \\
Pretest & 43,56 & 32 & 13,83 & & \\
\hline
\end{tabular}

Sumber: Data primer terolah, 2016. 
Tabel 3. Hasil uji regresi linier berganda

\begin{tabular}{|c|c|c|c|}
\hline Variabel & "Koefisien regresi & $\bar{t}$ & Sig \\
\hline X1 Tingkat pendidikan & 2,017 & 1,844 & 0,076 \\
\hline X2 Usia & $-0,606$ & 0,457 & 0,652 \\
\hline X3 Jumlah kepemilikan ternak & 3,655 & $-1,917$ & 0,066 \\
\hline X4 Pekerjaan peternak & $-0,820$ & 2,038 & 0,051 \\
\hline Konstanta & 35,090 & $-0,247$ & 0,807 \\
\hline F hitung & 3,178 & & 0,029 \\
\hline Adjust $R$ Square $\left(\mathrm{R}^{2}\right)$ & 0,219 & & \\
\hline Variabel dependen $=\mathrm{y}($ keberha & & & \\
\hline
\end{tabular}

Sumber : Data primer terolah, 2016.

sampai dengan 64 tahun (Arsyad, 1999). Menurut Setiana (2000) pada usia produktif seseorang mempunyai kondisi fisik, tindakan, serta kemampuan berfikir yang masih baik. Usia produktif lebih mudah untuk menerima inovasi baru guna meningkatkan dan mengembangkan usahanya.

Tingkat pendidikan peternak rata-rata adalah SD sebanyak 15 orang dengan persentase sebesar $46,88 \%$. Tingkat pendidikan peserta pelatihan dapat dilihat pada Tabel 1. Tingkat pendidikan peternak tersebut tergolong rendah. Rendahnya pendidikan peternak dikarenakan masalah ekonomi. Keterampilan dan pengetahuan peternak dengan tingkat pendidikan relatif rendah perlu ditingkatkan dengan cara memberikan pendidikan nonformal agar peternak rakyat tidak ketinggalan dengan perkembangan jaman dan teknologi khususnya dalam pengembangan usaha peternakan (Tiafery, 2016).

Jumlah kepemilikan ternak peserta pelatihan ini rata-rata adalah 2 ekor dengan kisaran 2-4 ekor sebanyak 23 orang. Jumlah kepemilikan ternak peserta pelatihan Tabel 1. Jumlah kepemilikan ternak sapi ini tergolong rendah dikarenakan usaha ini merupakan usaha sampingan yang dikelola secara tradisional. Hal ini sesuai pendapat Prawirokusumo (1990) yang menyatakan bahwa usaha yang bersifat tradisional diwakili oleh para petani dengan lahan sempit yang mempunyai 1 - 2 ekor ternak.

Mata pencaharian pokok peternak rata-rata adalah sebagai petani sebanyak 22 orang dengan persentase $68,75 \%$. Pekerjaan peternak peserta pelatihan dapat dilihat pada Tabel 1. Usaha peternakan sapi potong peternak tersebut merupakan usaha sampingan. Menurut Susanto (2003) menyatakan bahwa untuk menghadapi resiko usaha seperti kegagalan produksi, petani melakukan usaha sampingan sebagai salah satu sumber pendapatan untuk memenuhi kebutuhan pokok keluarga.

\section{Pengujian Instrumen}

Paired $t$ test. Peningkatan pengetahuan peserta yang mengikuti pelatihan dapat diukur dengan menggunakan uji paired $t$ test. Pengujian ini digunakan untuk mengukur apakah ada perbedaan pengetahuan peserta sebelum dilakukannya pelatihan dengan sesudah dilakukannya pelatihan. Hasil uji paired t test terdapat pada Tabel 2 .

Berdasarkan Tabel 2. terdapat perbedaan yang signifikan antara pengetahuan sebelum dan sesudah dilakukannya pelatihan $(\mathrm{p}<0,001)$. Nilai signifikasi 0,001 dan lebih kecil dari 0,05 . Hasil rata-rata dari nilai pretest dan posttest menunjukkan kenaikan dari 43,56 menjadi 61,69 atau naik sebesar 18,13 sehingga dapat disimpulkan bahwa pemberian pelatihan pengolahan pupuk organik berhasil dan efektif dengan ditunjukkan adanya peningkatan pengetahuan peternak sesudah diberikannya pelatihan.

Peningkatan pengetahuan sebagai tolak ukur dalam menentukan efektivitas suatu program pelatihan. Menurut pendapat Hasibuan (2005) bahwa pelatihan akan dikatakan berhasil apabila pelatihan yang dilakukan berjalan efektif yaitu bertambahnya pengetahuan, kemampuan dan ketrampilan terhadap materi pelatihan.

Uji regresi berganda. Uji regresi linier berganda digunakan untuk menguji apakah variabel independen berpengaruh terhadap variabel dependen. Variabel independen meliputi tingkat pendidikan, usia peternak, jumlah kepemilikan ternak dan pekerjaan peternak. Variabel dependen adalah keberhasilan pelatihan. Hasil uji regresi linier berganda dapat dilihat pada Tabel 3 .

$$
\begin{aligned}
& \mathrm{Y}=35,090+2,017 \mathrm{X}_{1}-0,606 \mathrm{X}_{2}+3,655 \mathrm{X}_{3}-0,820 \mathrm{X}_{4} \\
& \text { Keterangan } \\
& Y \quad=\text { Keberhasilan pelatihan } \\
& \mathrm{X}_{1}=\text { Tingkat pendidikan } \\
& \mathrm{X}_{2}=\text { Usia peternak } \\
& \mathrm{X}_{3}=\text { Jumlah kepemilikan ternak } \\
& \mathrm{X}_{4}=\text { Pekerjaan peternak }
\end{aligned}
$$

\section{Uji Statistik}

Uji Determinasi $\left(\mathrm{R}^{2}\right)$. Koefisien determinasi $\left(\mathrm{R}^{2}\right)$ mengukur seberapa jauh kemampuan sebuah model menerangkan variasi variabel dependen. Berdasarkan hasil pengujian determinasi $\left(\mathrm{R}^{2}\right)$ sebesar 0,320 atau 32 $\%$. Hal ini menunjukkan bahwa presentase sumbangan pengaruh variabel independen (tingkat pendidikan, usia peternak, jumlah kepemilikan ternak dan pekerjaan peternak) terhadap variabel dependen (keberhasilan pelatihan) sebesar $32 \%$ dan $68 \%$ dipengaruhi oleh variabel lain yang tidak dimasukkan dalam model ini.

Tabel 4. Hasil perhitungan koefisien determinasi

\begin{tabular}{lllll}
\hline \hline Model & $R$ & $R$ Square & $\begin{array}{l}\text { Adjusted } \\
R \text { Square }\end{array}$ & $\begin{array}{l}\text { Std. } \\
\text { error }\end{array}$ \\
\hline 1 & 0,566 & 0,320 & 0,219 & 16,869 \\
\hline
\end{tabular}

Sumber: Data primer terolah, 2016.

Uji F. Uji statistik F merupakan uji untuk mengetahui apakah model regresi dapat digunakan untuk memprediksi variabel dependen atau tidak 
(Priyatno, 2008). Pengujian menggunakan tingkat signifikansi 5\% (0,05). Hasil uji $\mathrm{F}$ dapat dilihat pada Tabel 5. Hasil uji F pada Tabel 5. menunjukkan bahwa nilai $\mathrm{F}$ hitung sebesar 2,871 dengan signifikansi 0,029 dan tingkat signifikansi $5 \%$ dengan df 1 (jumlah variabel-1) $=4$ dan df $2(n-k-1)=27$ maka diperoleh nilai $F_{\text {tabel }}$ sebesar 2,73. Menurut Priyatno (2008), jika $\mathrm{F}_{\text {hitung }}>\mathrm{F}_{\text {tabel }}$ maka Ho ditolak dan $\mathrm{F}_{\text {hitung }}<\mathrm{F}_{\text {tabel }}$ maka Ho diterima. Data menunjukkan nilai $\mathrm{F}_{\text {hitung }} 3,178>$ 2,73 sehingga dapat dikatakan bahwa koefisien regresi secara bersama-sama signifikan pada tingkat 5\% Kesimpulannya bahwa variabel tingkat pendidikan, usia peternak, jumlah kepemilikan ternak dan pekerjaan peternak secara bersama-sama berpengaruh terhadap keberhasilan pelatihan pengolahan pupuk organik.

Tabel 5. Hasil penghitungan uji F

\begin{tabular}{lccccc}
\hline \hline \multicolumn{1}{c}{ Model } & $\begin{array}{c}\text { Sum of } \\
\text { Squares }\end{array}$ & Df & $\begin{array}{c}\text { Mean } \\
\text { Square }\end{array}$ & F & Sig. \\
\hline Regression & 3617,72 & 4 & 904,43 & 3,18 & 0,029 \\
Residual & 7683,78 & 27 & 284,58 & & \\
Total & 11301,5 & 31 & & & \\
\hline
\end{tabular}

Uji t. Uji t digunakan untuk mengetahui apakah dalam model regresi variabel bebas secara parsial berpengaruh signifikan terhadap variabel terikat (Ghozali, 2011).

Hasil uji t dapat dilihat pada Tabel 6. Hasil analisis menunjukan bahwa tingkat pendidikan tidak berpengaruh terhadap keberhasilan pelatihan dengan nilai $\mathrm{p}=0,076$, nilai $\mathrm{df}=27$ pada tingkat kepercayaan $95 \%$ adalah 2,052 dengan $t_{\text {hitung }}>t_{\text {tabel }}$. Hal tersebut menunjukkan bahwa variabel tingkat pendidikan tidak berpengaruh secara parsial terhadap keberhasilan pelatihan. Tingkat pendidikan tidak berpengaruh terhadap keberhasilan pelatihan pengolahan pupuk organik karena tingkat pendidikan peternak tergolong rendah. Menurut Soekartawi (2005) pendidikan formal merupakan salah satu faktor yang mendukung kompetensi peternak, karena pengetahuan yang dimiliki dapat memengaruhi untuk berfikir lebih rasional, memilih alternatif dan cepat menerima atau melaksanakan suatu inovasi.

Tabel 6. Hasil penghitungan uji t

\begin{tabular}{|c|c|c|c|c|}
\hline Variabel & $\begin{array}{c}\text { t- } \\
\text { hitung }\end{array}$ & $\begin{array}{c}\mathrm{t}- \\
\text { tabel }\end{array}$ & Sig. & Ket \\
\hline $\begin{array}{l}\text { X1 Tingkat } \\
\text { pendidikan }\end{array}$ & 1,844 & 2,052 & 0,076 & $\begin{array}{c}\text { Tidak } \\
\text { signifikan }\end{array}$ \\
\hline X2 Usia & 0,457 & 2,052 & 0,652 & $\begin{array}{c}\text { Tidak } \\
\text { signifikan }\end{array}$ \\
\hline $\begin{array}{l}\text { X3 Jumlah } \\
\text { kepemilikan } \\
\text { ternak }\end{array}$ & $-1,917$ & 2,052 & 0,066 & $\begin{array}{c}\text { Tidak } \\
\text { signifikan }\end{array}$ \\
\hline $\begin{array}{l}\text { X4 Pekerjaan } \\
\text { peternak }\end{array}$ & 2,038 & 2,052 & 0,051 & $\begin{array}{c}\text { Tidak } \\
\text { signifikan } \\
\end{array}$ \\
\hline
\end{tabular}

Sumber : Data primer terolah, 2016

Variabel usia peternak sebesar 0,652 nilai $\mathrm{df}=27$ pada tingkat kepercayaan $95 \%$ adalah 2,052 dengan $\mathrm{t}_{\text {hitung }}<\mathrm{t}_{\text {tabel }}$ menunjukkan hasil yang tidak signifikan. Hal ini menunjukkan bahwa variabel usia tidak berpengaruh secara parsial terhadap keberhasilan pelatihan. Usia peternak tidak berpengaruh terhadap keberhasilan pelatihan pengolahan pupuk organik karena usia peternak yang tergolong produktif belum tentu menggambarkan pengetahuan dan ketrampilan yang dimiliki peternak.

Variabel jumlah kepemilikan ternak sebesar 0,066 nilai $\mathrm{df}=27$ pada tingkat kepercayaan $95 \%$ adalah 2,052 dengan $t_{\text {hitung }}<t_{\text {tabel }}$ menunjukkan hasil yang tidak signifikan. Hal ini menunjukkan bahwa variabel jumlah kepemilikan ternak tidak berpengaruh secara parsial terhadap keberhasilan pelatihan. Kepemilikan ternak sapi tidak berpengaruh terhadap keberhasilan pelatihan dikarenakan peternak rata-rata memiliki jumlah sapi tergolong rendah yang sebagian besar masih dikelola secara tradisional (Prawirokusumo,1990).

Variabel pekerjaan peternak sebesar 0,051 nilai $\mathrm{df}=27$ pada tingkat kepercayaan $95 \%$ adalah 2,052 dengan $t_{\text {hitung }}<\mathrm{t}_{\text {tabel }}$ menunjukkan hasil yang tidak signifikan. Hal ini menunjukkan bahwa variabel pekerjaan peternak tidak berpengaruh secara parsial terhadap keberhasilan pelatihan. Pekerjaan peternak tidak berpengaruh terhadap keberhasilan pelatihan pengolahan pupuk organik karena usaha peternakan merupakan pekerjaan sampingan sebagai salah satu sumber pendapatan untuk memenuhi kebutuhan pokok keluarga (Susanto, 2013).

\section{KESIMPULAN}

Kesimpulan dari penelitian ini adalah variabel tingkat pendidikan, usia peternak, jumlah kepemilikan ternak dan pekerjaan peternak secara bersama-sama berpengaruh terhadap keberhasilan pelatihan pengolahan pupuk organik, sedangkan variabel tingkat pendidikan, usia peternak, jumlah kepemilikan ternak dan pekerjaan peternak secara parsial tidak berpengaruh terhadap keberhasilan pelatihan pengolahan pupuk organik di Kecamatan Ngadirejo, Kabupaten Wonogiri.

\section{DAFTAR PUSTAKA}

Arsyad, L. 1999. Ekonomi Pembangunan. Edisi keempat. Universitas Gadjah Mada. Yogyakarta.

Aryogi, U., Umiyasih, D. B. Wijono dan D. Wahyono. 2000. Pengkajian rakitan teknologi penggemukan sapi potong. Dalam: Prosiding Seminar Hasil Penelitian/Pengkajian Balai Penelitian Tanaman Pangan Karangploso T.A. 1998/1999. Balai Penelitian Tanaman Pangan Karangploso. Malang.

Baba, S., Isbandi, T. Mardikanto dan Waridin. 2011. Faktor-faktor yang mempengaruhi tingkat partisipasi peternak sapi perah dalam penyuluhan di Kabupaten Enrekang. Jurnal Ilmu dan Teknologi Peternakan 1(3): 194-209.

Badan Pusat Statistik. 2012. Badan Perencanaan Pembangunan Daerah Ngadirojo. Bapedda. Wonogiri. 
Budiono, S. S. 2002. Faktor-faktor yang Mempengaruhi Tingkat Keefektifan Magang di Pusat Kegiatan Belajar Masyarakat (Kasus Pusat Kegiatan Belajar Masyarakat ALPA di Kelurahan Cirangrang, Kecamatan Babakan Ciparay, Kota Bandung). Tesis. Program Pascasarjana. Institut Pertanian Bogor. Bogor.

Ghozali, I. 2006. Aplikasi Analisis Multivariate dengan Program SPSS. Badan Penerbit Universitas Diponegoro. Semarang.

Handoko, T. H. 2009. Manajemen. BPFE-Yogyakarta. Yogyakarta.

Hasibuan. 2005. Manajemen Sumber Daya Manusia. Edisi Revisi. Bumi Aksara. Jakarta.

Kutner, M.H., C.J. Nachtsheim, and J. Neter. 2004. Applied Linear Regression Models. Fourth.ed. McGraw-Hill Companies, Incorporated. New York.

Prawirokusumo, S. 1990. Ilmu Usaha Tani. Edisi I. BPFE. Yogyakarta.

Priyatno, D. 2008. Mandiri Belajar SPSS untuk Analisis Data dan Uji Statistik, Edisi Pertama. Penerbit Mediakom. Jakarta.

Setiana. L. 2000. Teknik Penyuluhan dan Pemberdayaan Masyarakat. Ghalia Indonesia, Bogor.

Simamora, H. 2006. Manajemen Sumber Daya Manusia, Edisi 2. STIE YKPN, Yogyakarta.

Singarimbun, $M$ dan S. Effendi. 1997. Metode Penelitian Survei. Pustaka Lembaga Penelitian, Pendidikan dan Penerangan Ekonomi dan Sosial, Jakarta.

Soekartawi. 1995. Analisis Usahatani. Raja Grafindo Persada. Universitas Indonesia. Jakarta.

Soekartawi. 2005. Agroindustri dalam Perspektif Sosial Ekonomi. PT. Raja Grafindo Persada. Jakarta.

Sunyoto, D. 2009. Analisis Regresi dan Uji Hipotesis. Media Pressindo. Yogyakarta.

Susanto, W. 2003. Pendapatan Usahatani Pembibitan dan Pembesaran Sapi Potong Betina di Desa Tegahan, Kecamatan Grobogan, Kabupaten Grobogan, Jawa Tengah. Skripsi S1. Fakultas Peternakan Universitas Gadjah Mada. Yogyakarta.

Tiafery, 2016. Model Pemberdayaan Peternak Rakyat Dalam Pengembangan Usaha Penggemukan Sapi Potong Di Kecamatan Nogosari Kabupaten Boyolali. Skripsi. Fakultas Pertanian Universitas Sebelas Maret. Surakarta.

Undang-undang Nomer 13 Tahun 2003 Tentang Ketenagakerjaan.

Yusdja, Y., H. Malian, B. Winarso, R. Sayuti dan A. S. Bagyo. 2001. Analisis Kebijaksanaan Pengembangan Agribisnis Komoditas Unggulan Peternakan. Laporan Hasil Penelitian. Pusat Penelitian dan Pengembangan Sosial Ekonomi Pertanian. 